\title{
When Students Faced Online Learning in Coronavirus Times. A Case Study
}

\author{
Joanna Rabiega-Wiśniewska \\ Educational Research Institute, Poland
}

\begin{abstract}
In this paper, we present survey research which we conducted at Maria Grzegorzewska University, Poland, on April 2nd-10th, 2020. This work aimed at gathering information about online learning responses among full-time students of pedagogy. Due to the pandemic situation caused by coronavirus all activities at Polish universities have been suspended. Nevertheless, the learning process has been continued. For the first three weeks, academics and students have tried to adjust to a completely new way of education design and work. Our research provides insight into students' thoughts and emotions which accompanied them during those weeks of online learning courses. During the survey, respondents reported also their difficulties and observations regarding the quality of educational material, contact with lecturers, and reviewed assessments. In general, the majority of respondents have been doing well in this particular situation and positively evaluate the efforts of the lecturers. They find although online learning challenging. In the Introduction, we present circumstances of the research process and methodological background for the survey design. In the Methods section, we describe the survey structure and the respondent group, then we define the survey instruments. Next, the results are presented in two parts. First, we introduce the students' experiences and emotions associated with online learning. Second, we show what respondents said about their actual online courses taken in the studied period. In the following discussion, we present the most important findings and their possible explanation. In Conclusion, we summarize our analysis of the collected material and make recommendations for future research.
\end{abstract}

Keywords: distance learning; pandemic; remote learning; survey research; university education 